\title{
CEREBROVASCULAR ACCIDENTS IN PATIENTS OF CHRONIC RENAL FAILURE WITH ALTERED SENSORIUM PRESENTING IN EMERGENCY
}

\author{
Vinod Kumar', Ritu Bhagat², Achint Singh ${ }^{3}$
}

${ }^{1}$ Consultant Physician, Department of Medicine, JK Health Service, India.

${ }^{2}$ Senior Resident, Department of Pathology, GMC, Jammu, Jammu and Kashmir, India.

${ }^{3}$ Senior Resident, Department of Medicine, GMC, Jammu, Jammu and Kashmir, India.

\section{ABSTRACT}

\section{BACKGROUND}

Cerebrovascular disease is a devastating expression of vascular risk in CKD and yet, in comparison to cardiac disease, is relatively understudied. It is vital to understand the risks as well as benefits of established treatments directed at stroke treatment and prevention in all stages of CKD. We wanted to study stroke and stroke related mortality in patients of chronic renal failure.

\section{METHODS}

This is a prospective study of one-year duration, conducted from Dec. 2015 to Nov. 2016, at GMC, Jammu, which is a tertiary care centre. In our study, 64 patients were enrolled, 36 (56.25\%) were males and 28 (43.75) were females. Age of patients ranged from 18 to 60 years.

\section{RESULTS}

Out of 64 patients included in our study, 8 patients (12.5\%) had ischemic stroke, 6 patients (9.37\%) had haemorrhagic stroke while 2 patients $(3.12 \%)$ had both the lesions.

\section{CONCLUSIONS}

The incidence of stroke and related mortality is higher in CKD patients compared with that of the general population. Presence of anaemia, hypoalbuminemia, malnutrition, uraemia and hyperhomocysteinaemia in patients with CKD is associated with higher incidence of stroke.

HOW TO CITE THIS ARTICLE: Kumar V, Bhagat R, Singh A. Cerebrovascular accidents in patients of chronic renal failure with altered sensorium presenting in emergency. J. Evolution Med. Dent. Sci. 2019;8(16):1265-1267, D0I: 10.14260/jemds/2019/282

\section{BACKGROUND}

Chronic kidney disease/chronic renal failure encompasses a spectrum of different pathophysiological processes associated with abnormal kidney function and a progressive decline in glomerular filtration rate (GFR). Table 1 provides a widely accepted classification, based on guidelines of the National Kidney Foundation [Kidney Dialysis Outcomes Quality Initiative (KDOQI), in which stages of CKD are defined according to the estimated GFR.

The term chronic renal failure applies to the process of continuing significant irreversible reduction in nephron number and typically corresponds to CKD stages 3-5. The dispiriting term end stage renal disease represents a stage of CKD where the accumulation of toxins, fluid and electrolytes normally excreted by the kidneys results in the uremic syndrome. This syndrome leads to death unless the toxins are removed by renal replacement therapy, using dialysis or kidney transplantation. The incidence of stroke and strokerelated mortality is higher in CKD patients compared with the general population. Early interventions potentially decrease the incidence and associated mortality of stroke in CKD patients. ${ }^{1}$

'Financial or Other Competing Interest': None.

Submission 03-03-2019, Peer Review 10-04-2019,

Acceptance 17-04-2019, Published 22-04-2019.

Corresponding Author:

Dr. Achint Singh,

Senior Resident

Department of Medicine,

GMC, Jammu,

Jammu and Kashmir, India.

E-mail: drrkatil76@gmail.com

DOI: $10.14260 /$ jemds $/ 2019 / 282$

\section{(c) $($ ) $\$$}

\begin{tabular}{|c|c|}
\hline Stage & GFR, $\mathbf{~ m l}$ $\mathbf{~ m i n}$ per $\mathbf{1 . 7 3} \mathbf{~ m}^{\mathbf{2}}$ \\
\hline 0 & $>90$ \\
\hline 1 & $\geq 90$ \\
\hline 2 & $60-90$ \\
\hline 3 & $30-59$ \\
\hline 4 & $15-29$ \\
\hline $5 \quad$ & $<15$ \\
\hline \multicolumn{2}{|c|}{ Table 1. Stages of CKD } \\
\hline
\end{tabular}

\section{METHODS}

This is a prospective study for a period of one year from Dec. 2015 to Nov. 2016 performed in GMC, Jammu. 64 patients of chronic kidney disease of either sex fulfilling inclusion criteria were enrolled in the study. Sample size was taken based on the convenience of the study. Subjects under study were subjected to history, physical \& clinical examination, various lab. investigations, X-ray chest, Ultrasound for kidney size \& echotexture and NCCT Head. Got approval from IEC and consent was taken from all patients.

\section{Sampling Technique}

Convenient sampling.

\section{Inclusion Criteria}

Patients of chronic renal failure (CRF) admitted in emergency medical wards of GMC Jammu in a state of altered sensorium.

\section{Exclusion Criteria}

1. Patients with very poor general condition.

2. Patients with $<18$ years age.

3. Alcohol intake.

4. Significant cardiac, pulmonary, hepatic diseases. 


\section{Statistical Methods}

The statistical package for social science \{SPSS version 20 will be used for data analysis. Mean, median, and SD are used to describe quantitative data. Qualitative data are summarized using frequency and percentage

\section{RESULTS}

A total of 64 patients enrolled in our study. All subjects were known cases of CKD (already diagnosed).The observations made in the study are as under:

\begin{tabular}{|c|c|c|}
\hline Age Group (in Years) & Number & Percentage (\%) \\
\hline$<30$ & 5 & 7.81 \\
\hline $31-40$ & 10 & 15.62 \\
\hline $41-50$ & 26 & 40.62 \\
\hline $51-60$ & 23 & 35.93 \\
\hline Table 1. Age Distribution of Patients (n=64) \\
\hline \multicolumn{3}{|c|}{$50(26 ; 40.62 \%)$. } \\
\hline
\end{tabular}

\begin{tabular}{|c|c|c|}
\hline Sex & Number & Percentage (\%) \\
\hline Male & 36 & 56.25 \\
\hline Female & 28 & 43.75 \\
\hline Total & $\mathbf{6 4}$ & $\mathbf{1 0 0}$ \\
\hline \multicolumn{2}{|c|}{ Table 2. Sex Distribution of Patients (n=64) } \\
\hline $\begin{array}{r}\text { Male to female ratio among the patients was 1.28:1; with } \\
\text { males constituting 56.25\% and females 43.75\%. }\end{array}$ \\
\multicolumn{2}{|}{}
\end{tabular}

\begin{tabular}{|c|c|c|}
\hline Weight (in Kg) & Number & Percentage (\%) \\
\hline$\leq 50$ & 9 & 14.06 \\
\hline $51-60$ & 28 & 43.75 \\
\hline $61-70$ & 14 & 21.87 \\
\hline$>70$ & 13 & 20.31 \\
\hline
\end{tabular}

Table 3. Distribution of Patients According to Weight

Most patients were in the 51-60 Kg weight group (43.75\%; 28) followed by 61-70 Kg weight group.

\begin{tabular}{|c|c|c|}
\hline Comorbidity & Number & Percentage (\%) \\
\hline Hypertension & 55 & 85.93 \\
\hline Diabetes Mellitus & 39 & 60.93 \\
\hline Total & 64 & 100 \\
\hline \multicolumn{3}{|c|}{$\begin{array}{c}\text { Table 4. Distribution of Patients According to Co- } \\
\text { Morbidity }(n=64)\end{array}$} \\
\hline $\begin{array}{l}\text { In the present } \\
\text { hypertension wa } \\
\text { Diabetes mellitu }\end{array}$ & $\begin{array}{l}64 \text { patien } \\
\text { nt in } 58(8 \\
\text { resent in } 3\end{array}$ & $\begin{array}{l}\text { CKD, history of } \\
0) \text { and history of } \\
.93 \%) \text { patients. }\end{array}$ \\
\hline
\end{tabular}

\begin{tabular}{|c|c|c|}
\hline Complaint & Number & Percentage (\%) \\
\hline Drowsiness & 35 & 54.68 \\
\hline Hemiparesis & 5 & 7.81 \\
\hline Seizure & 4 & 6.25 \\
\hline Syncope & 2 & 3.125 \\
\hline Irrelevant Talking & 10 & 15.62 \\
\hline Others & 8 & 12.5 \\
\hline Total & 64 & 100 \\
\hline \multicolumn{3}{|c|}{$\begin{array}{l}\text { Table 5. Distribution of Patients According to Presenting } \\
\text { Symptoms }(n=64)\end{array}$} \\
\hline \multicolumn{3}{|c|}{$\begin{array}{l}\text { Most patients presented with chief complaints of drowsiness } \\
\qquad(35 ; 54.68 \%) .\end{array}$} \\
\hline
\end{tabular}

\begin{tabular}{|c|c|c|}
\hline SBP & Number & Percentage (\%) \\
\hline$\leq 140$ & 11 & 17.18 \\
\hline $141-160$ & 17 & 26.56 \\
\hline $161-180$ & 26 & 40.62 \\
\hline$>180$ & 10 & 15.62 \\
\hline Total & $\mathbf{6 4}$ & $\mathbf{1 0 0}$ \\
\hline \multicolumn{2}{|c|}{ Table 6. Distribution of Patients According to SBP (n=64) } \\
\hline \multicolumn{2}{|c|}{ Most patients had SBP between 161-180 (26; $40.62 \%) ;$} \\
followed by 141-160 (17; 26.56\%).
\end{tabular}

\begin{tabular}{|c|c|c|}
\hline DBP & Number & Percentage (\%) \\
\hline$\leq 80$ & 9 & 14.06 \\
\hline $81-90$ & 17 & 26.56 \\
\hline $91-100$ & 23 & 35.93 \\
\hline$>100$ & 15 & 23.43 \\
\hline Total & $\mathbf{6 4}$ & $\mathbf{1 0 0}$ \\
\hline
\end{tabular}

Table 7. Distribution of Patients According to DBP ( $n=64)$ Most of patients had DBP between 91-100 Hg (23; 35.93\%).

\begin{tabular}{|c|c|c|}
\hline Hg (g/dl) & Number & Percentage (\%) \\
\hline$<8$ & 19 & 29.68 \\
\hline $8-10$ & 43 & 67.18 \\
\hline$>10$ & 2 & 3.12 \\
\hline Total & $\mathbf{6 4}$ & $\mathbf{1 0 0}$ \\
\hline \multicolumn{2}{|c|}{ Table 8. Distribution of Patients According to } \\
Haemoglobin (n=64) \\
\hline \multicolumn{2}{|c|}{ Most patients had Hb between 8-10 gm/dl (43; 67.18\%). } \\
\hline
\end{tabular}

\begin{tabular}{|c|c|c|}
\hline GFR (ml/min $/ \mathbf{1 . 7 3} \mathbf{~ m}^{\mathbf{2}}$ & Number & Percentage (\%) \\
\hline$<15$ (Stage V) & 53 & 82.81 \\
\hline $15-29$ (Stage IV) & 7 & 10.93 \\
\hline $30-44$ (Stage IIIa) & 2 & 3.12 \\
\hline $45-60$ (Stage IIIb) & 2 & 3.12 \\
\hline
\end{tabular}

Table 9. Distribution of Patients According to GFR ( $n=64)$

Most of the patients had stage V CKD (53; 82.81\%).

\begin{tabular}{|c|c|c|}
\hline Mode of Treatment & Number & Percentage (\%) \\
\hline Conservative & 22 & 34.37 \\
\hline HD & 32 & 50 \\
\hline PD & 10 & 15.62 \\
\hline Total & $\mathbf{6 4}$ & $\mathbf{1 0 0}$ \\
\hline
\end{tabular}

Table 10. Distribution of Patients According to Mode of Treatment ( $n=64)$

Most patients taken in study were on maintenance dialysis (HD) $42 ; 65.61 \% .32$ patients (50\%) were on haemodialysis and 10 patients $(15.62 \%)$ were on peritoneal dialysis. Also 22 patients $(34.37 \%)$ were on conservative treatment.

\begin{tabular}{|c|c|c|}
\hline Findings on NCCT Head & Number & Percentage (\%) \\
\hline Normal & 10 & 15.62 \\
\hline Cerebral Atrophy & 42 & 65.62 \\
\hline Ischemic Lesions & 8 & 12.5 \\
\hline Haemorrhagic Lesions & 6 & 9.3 \\
\hline Endocranial Calcification & 6 & 9.3 \\
\hline Others & 4 & 6.25 \\
\hline
\end{tabular}

Most common CT Head finding is cerebral atrophy (42; 65.62\%). Other findings included bilateral cerebral hypodensities, bilateral basal ganglia hypodensities, ICSOL, etc. Ischemic stroke was seen in 8 patients $(12.5 \%)$; out of which 5 patients has lacunar infarcts. Haemorrhagic stroke occurred in 6 patients (9.3\%). Ischemic stroke with 
haemorrhagic transformation was seen in 2 patients. Endocranial calcification including bilateral basal ganglia calcifications were seen in 6 patients. Most common site for haemorrhagic stroke was found to be thalamus ( 3 patients) followed by basal ganglia ( 2 patients) and cerebral cortex (1 patient). NCCT Head was reported normal in 10 (15.62\%) patients.

\section{DISCUSSION}

Chronic kidney disease is a progressive loss in renal function characterised by nephron damage and depletion that leads to necessity of dialysis to avoid death from uraemia or renal transplantation. This condition is associated with several pathological conditions such as metabolic acidosis, hypocalcaemia, hyperphosphatemia, sodium and potassium alteration, protein energy malnutrition, sexual dysfunction, neurological disorders, hypertension and other cardiac or pulmonary pathologies, vascular calcification, dermatological manifestations, immunological deficit with susceptibility to infections, anaemia, haemorrhagic diathesis and other disorders. Out of 64 patients, $53(82.81 \%)$ had CKD Stage V, 7 (10.93\%) had CKD Stage IV, 2 (3.12\%) had CKD Stage IIIb, 2 (3.12\%) had CKD Stage IIIa.

55 patients were hypertensive and 39 were diabetic. All the patients were presenting with neurological complaints like drowsiness, hemiparesis, facial palsy, seizure, sudden syncope, irrelevant talking, etc.

Out of 64 patients, 16 patients (25\%) were found to have stroke. Out of 16 patients, 8 patients (50\%) had ischemic stroke, 6 patients (37.5\%) had haemorrhagic stroke and 2 patients $(12.5 \%)$ had haemorrhagic transformation of ischemic stroke. In a similar study it was found that stroke due to cerebral infarction in $48.14 \%$ and due to cerebral haemorrhage in $40.7 \%$ of the patients in a study of 27 patients of stroke with CKD. ${ }^{2}$

Out of 6 patients with haemorrhagic stroke in our study, 3 patients (50\%) had thalamic bleed, 2 patients (33.33\%) had basal ganglia bleed and 1 patient $(16.67 \%)$ had subcortical bleed. A study also reported distribution of haemorrhagic stroke in CKD as thalamus in $38.46 \%$, basal ganglia in $38.46 \%$, subcortical in $15.38 \%$ and cerebellum in $7.69 \%$ of the patients.

Out of overall 42 patients on dialysis treatment, 31 patients had cerebral atrophy $(73.8 \%) .^{3}$

Moreover, in our study, out of 22 patients on conservative treatment, 5 patients had stroke $(22.7 \%)$. Out of 32 patients on haemodialysis treatment, 9 patients had stroke (28.12\%). Out of 10 patients on peritoneal dialysis treatment, 2 patients had stroke (20\%).

Furthermore, endocranial calcification (including bilateral basal ganglia calcification, pineal gland calcification, choroid plexus calcification, cortical calcification) was found in 6 patients (9.3\%). Savazzi GM et al $(2001)^{4}$ also found endocranial calcification in $9.6 \%$ patients in a study of 166 patients.
Intracranial space occupying lesions were noted in 2 patients (3.125\%).

Moreover, bilateral basal ganglia hypodensities were noted in 2 patients (3.125\%). Eun Ja Lee et al (2007) ${ }^{5}$ also studied 4 patients with diabetic mellitus and chronic renal failure who developed sudden choreic movement disorder. Neuroimaging revealed bilateral symmetrical basal ganglia lesions. After haemodialysis, lesions regressed significantly in all 4 patients and this sensorium also improved. In a similar study by Wang HC et al (2003) ${ }^{6}$ studied 12 patients of chronic renal failure with abnormal body movements and documented neuroimaging findings of symmetrical bilateral basal ganglia changes.

Out of 64 patients, NCCT Head was reported normal in 10 patients $(15.62 \%)$.

\section{CONCLUSIONS}

The increasing prevalence of neurological symptoms has resulted in studies on central nervous system lesions via radio-imaging like NCCT head in patients of chronic renal failure. The increasing number of patients with ESRD requiring dialysis therapy is becoming a worldwide public health problem and puts a substantial burden on healthcare resources. In fact, dialysis can directly or indirectly be associated with dialysis dementia, disequilibrium syndrome, aggravations of atherosclerosis, cerebrovascular accidents, etc. Appropriate use of these procedures helps in managing patient's cerebrovascular health and associated neurologic morbidity across the lifespan.

\section{REFERENCES}

[1] Saeed F, Kousar N, Qureshi K, et al. A review of risk factors for stroke in patients with chronic kidney disease. J Vasc Interv Neurol 2009;2(1):126-31.

[2] Krishna PR, Naresh S, Krishna GS, et al. Stroke in chronic kidney disease. Indian $J$ Nephrol 2009;19(1):5-7.

[3] Cusmano F, Savazzi GM. Cerebral computer tomography in uremic and hemodialyzed patients. J Comput Assist Tomogr 1986;10(4):567-70.

[4] Savazzi GM, Cusmano F, Musini S. Cerebral imaging changes in patients with chronic renal failure treated conservatively or in hemodialysis. Nephron 2001;89(1):31-6.

[5] Lee EJ, Park JH, Ihn YK, et al. Acute bilateral basal ganglia lesions in diabetic uraemia: diffusion weighted MRI. Neuroimaging 2007;49(12):1009-13.

[6] Wang HC, Cheng SJ. The syndrome of acute bilateral basal ganglia lesions in diabetic uremic patients. J Neurol 2003;250(8):948-55. 